\title{
Inhibition by D-Glutamate of Growth and Glutamate Dehydrogenase Activity of Neurospora crassa
}

\author{
By HADARA ARKIN AND N. GROSSOWICZ \\ Department of Bacteriology, The Hebrew University-Hadassah Medical \\ School, Jerusalem, Israel
}

(Accepted for publication 27 January 1970)

\begin{abstract}
SUMMARY
D-Glutamic acid (D-glu) inhibited strongly the growth of two strains of Neurospora crassa in a minimal medium. The inhibition was completely annulled by equivalent concentrations of L-glutamic acid (L-glu) or L-glutamine. D-Glu also inhibited glutamate dehydrogenase (GDH) and was only antagonized completely by Io equivalents of L-glu. D-Glu in media containing L-glu increased GDH-activity, presumably by de-repression. D-Glu showed no effect on glutamine synthetase and $\gamma$-glutamyl transferase activities. Inhibition of growth of $N$. crassa by D-glu thus seems due to the interference with glutamate synthesis by inhibition of GDH-activity.
\end{abstract}

\section{INTRODUCTION}

Neurospora crassa is a prototrophic fungus which grows well in a minimal medium consisting of ammonia, glucose and various inorganic salts (Beadle \& Tatum, I94I). The $\alpha$-ketoglutarate $(\alpha-\mathrm{kg})$ formed from the sugar in the tricarboxylic acid cycle (Strauss, 1955; Krebs \& Lowenstein, 1960) is converted to glutamate in the presence of ammonia and the glutamate dehydrogenase enzyme (GDH). The glutamate then participates both directly in protein synthesis and as an intermediate in the production of many other amino acids by transamination and other reactions (Fincham, 195I $a, b$ ). The GDH enzyme is therefore of pivotal importance to this organism.

Certain D-amino acids inhibit growth of certain bacteria in the absence of the L-isomers (Fox, Fling \& Bollenback, 1944; Prescott, Schweigert, Lyman \& Kuiken, 1949). D-Amino acids also inhibit the enzymic activity of the corresponding natural amino acid. Thus, for example, D-asparagine inhibits L-asparaginase in extracts of Mycobacterium phlei (Grossowicz \& Halpern, 1956; Grossowicz \& Halpern, 1957), and D-glutamic acid causes partial inhibition of the L-glutamic decarboxylase of Escherichia coli (Roberts, I953). Olson \& Anfinsen (1953) reported that D-glutamic acid inhibits the activity of crystalline GDH from beef liver. The present paper deals with the inhibition of growth and of GDH-activity of Neurospora crassa by D-glutamic acid (D-glu) and with the mechanism of these inhibitions.

\section{METHODS}

Media. A minimal medium prepared according to Horowitz \& Beadle (1943) at a $5: 4$ concentration was distributed in $4 \mathrm{ml}$. amounts into test-tubes $(18 \times 150 \mathrm{~mm}$.). Water or substances to be tested were added to the medium and its final volume 
brought to $5 \mathrm{ml}$. L-Glutamic acid (L-glu) and/or D-glu were added in suitable amounts to the medium before sterilization; sucrose and L-glutamine were sterilized separately (the last by filtration) and added aseptically to the sterile medium.

Strains. Most of the work was done with strain no. I from the collection of the Bacteriology Department which was sensitive to D-glu. Some experiments were done with the wild-type strain no. 262 (STA-4) obtained from Dr B. D. Sanwal (Department of Microbiology, The University of Manitoba, Winnipeg, Canada). Another strain sensitive to inhibition by D-glu was IMI-3I288, a mutant which requires $p$-aminobenzoic acid for growth. Two other strains (LBS 304.59 and a local isolate) proved much more resistant to D-glu.

Estimation of growth. Each tube was inoculated with $0.2 \mathrm{ml}$. of a barely turbid spore suspension of the no. I strain of Neurospora crassa prepared from a $48 \mathrm{hr}$ culture grown on Bacto-Neurospora Culture Agar (Difco); the tubes were incubated at $30^{\circ}$ for 2 to 3 days in a sloped position of $15^{\circ}$ above horizontal to ensure adequate aeration.

After incubation, the mycelium was separated from the medium by filtration through filter paper on a small Büchner funnel. The mycelium was thoroughly washed with distilled water, air dried and then dried in an oven at $80^{\circ}$ for 2 to $3 \mathrm{hr}$. The different mycelial mats were weighed separately on a Sauter spring balance of $0.2 \mathrm{mg}$. sensitivity. With the Horowitz-Beadle medium, without any additions, the dry weights of the mycelia were between 18 and $25 \mathrm{mg}$./tube.

Growth of Neurospora for enzyme preparations. To obtain enough enzyme, the fungus was grown in 21 . Erlenmeyer flasks containing $500 \mathrm{ml}$. medium and shaken at $30^{\circ}$ for 2 days.

Acetone dry powder preparation. After incubation, the mycelium was collected by filtration; 20 vol. cooled acetone/g. mycelium were added and homogenized for 2 to $3 \mathrm{~min}$. at maximum speed in an M.S.E. Atomix-homogenizer. The acetone was removed by decantation and filtration through a Büchner funnel and the powdered mycelium was dried rapidly on filter sheets, yielding a fine flaky substance; I g. of the acetone dry powder was extracted with $20 \mathrm{ml} .0 .05 \mathrm{M}-\mathrm{K}$-potassium phosphate (pH 8.0) for I hr in the cold, centrifuged at $10,000 \mathrm{rev} . / \mathrm{min}$. for $15 \mathrm{~min}$. The supernatant fluid was dialysed in the cold against a large volume of the same buffer and served as the GDH enzyme preparation.

Protein was measured by the biuret method modified according to Gornall, Bardawill \& David (1949).

Assay of $G D H$-activity. The enzymic activity was assayed at $35^{\circ}$ by measuring the changes in optical density (O.D.) at $340 \mathrm{~m} \mu$ in a S.P. Unicam Spectrophotometer due to oxidation of the reduced nicotinamide dinucleotide phosphate (NADPH) or to the reduction of NADP. The reaction mixture for glutamate synthesis (forward reaction) contained the following components (unless otherwise stated) in a final volume of $3 \mathrm{ml}$.: $\alpha$-ketoglutarate, $20 \mu$ mole; ammonium sulphate, Io $\mu$ mole; phosphate buffer ( $\mathrm{pH} 7.5$ ), O.I M; NADPH, $300 \mu \mathrm{g}$.; enzyme protein, $250 \mu \mathrm{g}$. For the reverse reaction the mixture was composed of L-glu, $80 \mu$ mole, phosphate buffer ( $\mathrm{pH} \mathrm{8.3),} \mathrm{0.I} \mathrm{M;}$ NADP, $300 \mu \mathrm{g}$.; enzyme protein, $750 \mu \mathrm{g}$. The reaction was started by adding enzyme. The differences in extinction were examined every 15 to $30 \mathrm{sec}$. for $3 \mathrm{~min}$. 


\section{RESULTS}

Effect of D-glutamate on growth of Neurospora crassa. D-Glu in the minimal medium inhibited growth; at 0.5 to $\mathrm{I} \cdot 0 \mu \mathrm{mole} / \mathrm{ml}$. D-glu caused $50 \%$ inhibition over 2 days but less inhibition after 3 days (Table I). The strain no. 262 was slightly less sensitive than the departmental culture (strain no. I).

Effect of L-glu and L-glutamine on growth inhibition caused by D-glu. As Table 2 shows, the growth inhibition by D-glu was overcome by either L-glu or glutamine at 2 to 3 times lower molar concentrations.

Table I. Effect of D-glutamate (D-glu) on growth of Neurospora crassa

Tubes containing $5 \mathrm{ml}$. of minimal medium with increasing concentrations of D-glu were inoculated with $0.2 \mathrm{ml}$. of barely turbid spore suspensions of the respective Neurospora crassa strains. After 3 days at $30^{\circ}$ the mycelia were removed by filtration through small Büchner funnels, washed with distilled water, dried to constant weight for $2 \mathrm{hr}$ at $80^{\circ}$, and weighed.

\begin{tabular}{|c|c|c|c|c|}
\hline \multirow[b]{2}{*}{$\begin{array}{l}\text { D-glu added } \\
(\mu \mathrm{mole} / \mathrm{ml} .)\end{array}$} & \multicolumn{2}{|c|}{ Strain no. I } & \multicolumn{2}{|c|}{ Strain no. 262} \\
\hline & $\begin{array}{c}\text { Growth } \\
\text { (mg. dry wt) }\end{array}$ & $\begin{array}{c}\text { Inhibition } \\
(\%)\end{array}$ & $\begin{array}{c}\text { Growth } \\
\text { (mg. dry wt) }\end{array}$ & $\begin{array}{c}\text { Inhibition } \\
(\%)\end{array}$ \\
\hline 0 & 21 & 一 & 25 & 一 \\
\hline 0.2 & I 6 & 24 & 22 & 12 \\
\hline 0.4 & 13 & 38 & 17 & 32 \\
\hline 0.6 & 12 & 43 & 15 & 40 \\
\hline$I \cdot 0$ & 10 & 52 & 13 & 44 \\
\hline $2 \cdot 0$ & 5 & 76 & I0 & 60 \\
\hline $3 \cdot 0$ & $2 \cdot 5$ & 88 & 8 & 68 \\
\hline $4^{\circ} 0$ & $I \cdot 5$ & 93 & 5 & 80 \\
\hline $5 \cdot 0$ & 0.5 & 98 & I & 96 \\
\hline
\end{tabular}

Table 2. Effect of L-glu and glutamine on the growth inhibition caused by D-glu

Strain no. I. Growth in mg. dry wt after 3 days at $30^{\circ}$.

\begin{tabular}{|c|c|c|c|c|c|c|c|c|c|}
\hline \multirow{2}{*}{$\begin{array}{c}\text { D-glu } \\
\text { added } \\
(\mu \mathrm{mole} / \mathrm{ml} .)\end{array}$} & \multirow[b]{2}{*}{0.0} & \multicolumn{4}{|c|}{ L-glu $(\mu \mathrm{mole} / \mathrm{ml})}$. & \multicolumn{4}{|c|}{ Glutamine ( $\mu$ mole $/ \mathrm{ml})}$. \\
\hline & & 0.2 & 0.3 & 0.6 & $I \cdot O$ & 0.2 & 0.3 & 0.6 & 1.0 \\
\hline 0 & 18 & 20 & 20 & 20 & 20 & 18 & 18.5 & 18.5 & 18 \\
\hline 0.3 & 10.5 & 18 & 19 & 20 & 20 & 17 & 17.5 & 18 & 18 \\
\hline 0.6 & 9 & 16 & 18 & I9 & 20 & 17 & 17.5 & 19 & 19 \\
\hline $1 \cdot 0$ & 7 & 15 & 17.5 & 18 & 19 & I4 & 18 & 18 & 19 \\
\hline
\end{tabular}

Effect of D-glu on enzymes involved in the metabolism of glutamic acid and glutamine. $\mathrm{D}$-Glu had no effect on glutamine synthetase and $\gamma$-glutamyl transferase but glutamate dehydrogenase (GDH) activity, as preliminary experiments indicated, was inhibited.

Inhibition of the forward reaction: synthesis of glutamate. Enzymic activity decreased with the increase of the D-glu concentration; $50 \%$ inhibition was caused at a molar D-glu: $\alpha$-kg ratio of I:I (Fig. I). Similar results were obtained with the strain no. 262 .

Inhibition of the backward reaction: oxidative deamination of glutamate. The reversal of glutamate formation was inhibited by D-glu in a similar manner as the forward reaction (Fig. 2); $50 \%$ inhibition was obtained at a ratio inhibitor:substrate of $1: 2$ to $I: 4$. 
Effect of $\alpha$-ketoglutarate $(\alpha-k g)$. In the absence of D-glu, $20 \mu$ mole $\alpha$-kg saturated $0.25 \mathrm{mg}$. enzyme but with $20 \mu$ mole D-glu, $80 \mu$ mole $\alpha$-kg were required to overcome the inhibition completely. When the results were plotted according to Lineweaver \& Burk (1934), the two lines intersected on the ordinate.

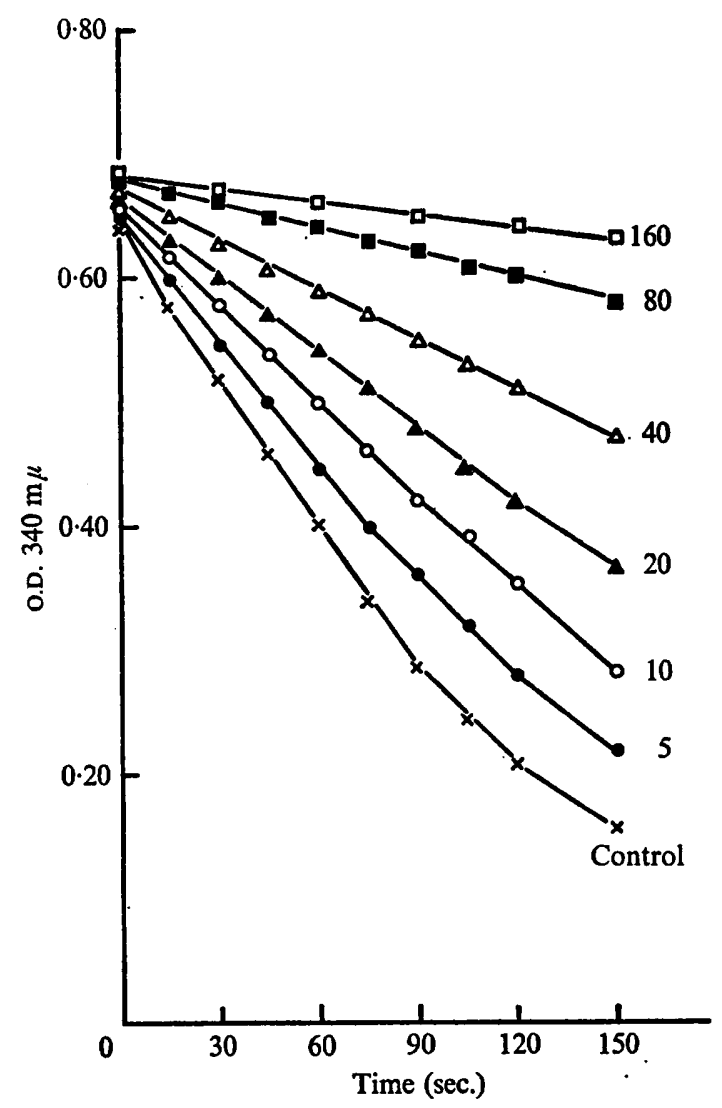

Fig. I

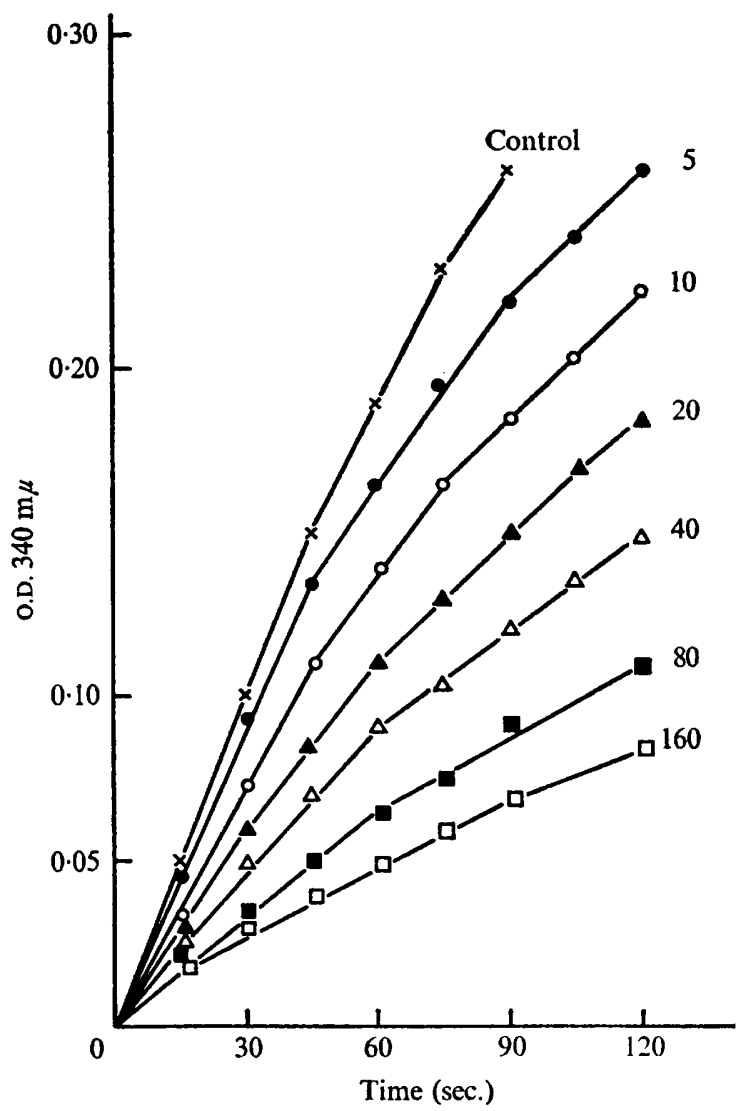

Fig. 2

Fig. I. Glutamic dehydrogenase activity (forward reaction) as a function of the D-glu concentration. The reaction mixture contained : $\alpha-\mathrm{kg}, 20 \mu$ mole; ammonium sulphate, Io $\mu$ mole; NADPH, $300 \mu$ g.; enzyme protein, $0.25 \mathrm{mg}$.; K-phosphate buffer ( $\mathrm{pH} \mathrm{7.5),} 0.1 \mathrm{M}$; total volume, $3 \mathrm{ml}$. D-Glu $\mu$ mole as indicated in the figure.

Fig. 2. Inhibition of the oxidative deamination of glutamate (backward reaction) by D-glu. The reaction mixture contained : L-glu, $80 \mu$ mole; NADP, $300 \mu \mathrm{g}$.; enzyme protein, $0.75 \mathrm{mg}$.; phosphate buffer (pH 8.3), $0.1 \mathrm{M}$; total vol., $3 \mathrm{ml}$. D-Glu $\mu$ mole as indicated in figure.

Effect of ammonia. Increasing the concentration of ammonia hardly affected the inhibition of glutamate synthesis by D-glu: a fivefold increase in the ammonia concentration decreased the inhibition by $10 \%$ only.

Effect of $L$-glu. In the absence of D-glu, $80 \mu$ mole L-glu were almost enough to saturate the enzyme $(750 \mu \mathrm{g}$. protein): considerably higher concentrations of L-glu caused only a slight increase in activity. Addition of $20 \mu$ mole D-glu caused $50 \%$ inhibition, but inhibition was not completely annulled until the L-glu concentration was increased sixfold, to a molar ratio of 24 : I of L-glu: D-glu (Table 3). 
Effect of D-glu and L-glu on GDH-formation. The formation of many enzymes is repressed by the presence, during growth, of the product of the enzymic reaction. The NADPH-dependent GDH-activity of Neurospora crassa is repressed by L-glutamate and related amino acids (Sanwal \& Lata, $1962 a, b$ ). To find out about the regulatory control of this biosynthetic enzyme the effect of D-glu on GDH-formation was investigated.

Table 3. Rate of oxidative deamination of $L$-glutamic acid in the presence and absence of $D-g l u$

o.D. at $340 \mathrm{~m} \mu$ after $60 \mathrm{sec}$.

$\begin{array}{ccc}\begin{array}{c}\text { L-glu } \\ (\mu \text { mole })\end{array} & \text { Without D-glu } & \begin{array}{c}\text { D-glu added } \\ (20 \mu \text { mole })\end{array} \\ 10 & 0.055 & - \\ 20 & 0.095 & 0.040 \\ 40 & 0.175 & 0.065 \\ 80 & 0.195 & 0.105 \\ 120 & 0.20 & 0.12 \\ 160 & 0.22 & - \\ 320 & 0.225 & 0.16 \\ 480 & - & 0.22\end{array}$

Table 4. Glutamate dehydrogenase formation by Neurospora crassa grown in different media with or without D-glutamic acid

\begin{tabular}{|c|c|}
\hline Neurospora grown in & $\begin{array}{l}\text { D-glu added } \\
(\mu \mathrm{mole} / \mathrm{ml}) \text { ) }\end{array}$ \\
\hline
\end{tabular}

Expt. I

Minimal medium

Minimal medium + L-glu, $0.5 \mathrm{M}$

Rich medium

Expt. 2

Minimal medium

Minimal medium

Expt. 3

Minimal medium

Minimal medium

Minimal medium + L-glu, O. I M

Minimal medium + L-glu, O.I M

Minimal medium + L-glu, $0.1 \mathrm{M}$

Expt. 4

Rich medium

Rich medium

Rich medium

0250

D-glu added

0

o

0

0.5

o 280

$0.7 \quad 360$

0

$50 \cdot 0$

I00.0

0
0
$75 \cdot 0$
$100 \cdot 0$
250
50

40

320

600

360
60

80

160

40

100

170

Neurospora crassa no. I was grown in the minimal medium in Erlenmeyer flasks with and without $0.5 \mathrm{~mm}$-D-glu, which caused a $50 \%$ inhibition of growth. After 2 days at $30^{\circ}$ the mycelial mats were harvested and extracts prepared as described under Methods. The enzyme preparation from the D-glu-grown culture was almost twice as active as that obtained from the control culture (see below).

To test the effect of L-glutamate and metabolically related substances on GDHformation, Neurospora crassa was grown for 2 days in various media without and with D-glu: (a) minimal medium; $(b)$ minimal medium + 0.05 M-L-glu; $(c)$ yeast-peptone 
medium (rich medium). Preparations were obtained from the cultures and tested for GDH-activity. As Table 4 shows, addition of L-glu to the growth medium yielded extracts with considerably lower GDH-activity (25\%) than the controls. The extracts from cultures grown in the rich medium were even less active ( $15 \%$ ) than that of the L-glu-grown culture. On the other hand, extracts from cultures grown on the same medium supplemented with D-glu possessed considerable GDH-activity (Table 4, Expt. 4).

\section{DISCUSSION}

D-Glutamic acid (D-glu), the unnatural stereoisomer of L-glutamic acid (L-glu), was a potent growth inhibitor for the two Neurospora crassa strains studied, and its inhibition was easily annulled by L-glu or glutamine at 2.5 times smaller molar concentrations. Although cell-free preparations showed no glutaminase activity, it is not certain that the glutamine itself, and not some enzymic degradation product, was responsible for the annullment of the growth inhibition since glutamine did not annul inhibition of GDH-activity (see below).

Much less D-glu was required to inhibit growth than GDH-activity; growth inhibition was annulled by less than the equimolar L-glu. In contrast, inhibition of the GDHactivity was overcome only by 10 -fold or higher molar concentrations of the natural amino acid. The inhibition of growth seems therefore to be non-competitive, due to the production of limiting concentrations of L-glu by the inhibited enzyme; indeed, addition of L-glu, the product of the enzymic reaction, restored growth to its full extent.

In accordance with the findings of Sanwal \& Lata (I962 $a, b)$, formation of NADPHdependent GDH enzyme was repressed by L-glu. Of interest is the finding that D-glu increased GDH-formation. L-Glu, the product of GDH-catalysed reaction, serves as a substrate in the biosynthesis of various amino acids and therefore should be used up rapidly, rather than accumulate in the cell. Thus, repression of GDH-activity can be expected to be pronounced only in a glutamate-containing medium, as was shown in our experiments (Table 4). D-Glu lowers the availability of L-glu to the fungus and so de-represses the formation of enzyme. D-Glu stimulation of enzyme formation resembles anthranilic acid and 3-methyl anthranilic acid induction of tryptophan synthetase formation (Lester \& Yanofsky, 196I).

\section{REFERENCES}

Beadle, G. W. L. \& TATUM, E. L. (1941). Genetic control of biochemical reactions in Neurospora. Proceedings of the National Academy of Sciences of the United States of America 27, 499.

Fincham, J. R. S. (195 I a). Transaminases in Neurospora crassa. Nature, London I68, 957.

FinchaM, J. R. S. (1951 $b$ ). The occurrence of glutamic dehydrogenase in Neurospora and its apparent absence in certain mutant strains. Journal of General Microbiology 5, 793.

Fox, S. W., Fling, M. \& Bollendack, G. W. (1944). Inhibition by bacterial growth by D-leucine. Journal of Biological Chemistry 155, 465.

Gornall, A. G., Bardawill, C. J. \& David, M. M. (1949). Determination of serum proteins by means of the biuret reaction. Journal of Biological Chemistry 177, 751 .

GrossowicZ, N. \& HALPERN, Y. S. (1956). Inhibition of L-asparaginase in extracts of Mycobacterium phlei by D-asparagine. Nature, London $\mathbf{1 7 7}, 625$.

Grossowicz, N. \& HALPERN, Y.S. (1957). Enzymatic transfer and hydrolysis involving glutamine and asparagine. Journal of Biological Chemistry 228, 643.

Horowitz, N. H. \& BeAdLE, G. W. (1943). A microbiological method for the determination of choline by use of a mutant of Neurospora. Journal of Biological Chemistry 150, 325. 
Krebs, H. A. \& Lowenstern, J. M. (1960). The tricarboxylic acid cycle. In Metabolic Pathways, vol. I, p. I 29. Edited by D. M. Greenberg, New York and London: Academic Press.

LESTER, G. \& YANOFSKY, C. (I96I). Influence of 3-methylanthranilic and anthranilic acids on the formation of tryptophan synthetase in Escherichia coli. Journal of Bacteriology 8I, 8I.

LINEWEAVER, H. \& BURK, D. (1934). The determination of enzyme dissociation constants. Journal of the American Chemical Society 56, 658.

Olson, J. A. \& ANFInsEn, C. B. (1953). Kinetics and equilibrium studies on crystalline L-glutamic acid dehydrogenase. Journal of Biological Chemistry 202, $84 \mathrm{I}$.

Prescott, J. M., Schweigert, B. S., Lyman, C. M. \& Kuiken, K. A. (I949). The effect of D-tryptophane on the utilization of the L-isomer by some lactic acid bacteria. Journal of Biological Chemistry $\mathbf{1 7 8}, 727$.

ROBERTS, E (1953). Further studies of inhibition of bacterial glutamine decarboxylase. Journal of Biological Chemistry 202, 359.

Sanwal, B. D. \& LATA, M. (1962a). Effect of glutamic acid on formation of two glutamic acid dehydrogenases of Neurospora. Biochemical and Biophysical Research Communications 6, 404.

SANWAL, B. D. \& LATA, M. (1962 b). Concurrent regulation of glutamic acid dehydrogenase of Neurospora. Archives of Biochemistry and Biophysics 97, 582.

STRAuSs, B. S. (1955). Studies on the metabolism of acetate by acetate-requiring mutants of Neurospora crassa. Archives of Biochemistry and Biophysics 55, 77. 